\title{
Enhanced Field Electron Emission from Photocurrent Treated Nanostructured Indium Oxide Films
}

\author{
Zhenglin $\mathrm{Li}^{1}$,a , Fuyuan $\mathrm{Si}^{1}$, Miaomiao Wang ${ }^{1}$, Weigang $\mathrm{He}^{1}$ and Yuwei Zhang ${ }^{1}$ \\ ${ }^{1}$ College of Electrical and Information Engineering, Guangxi University of Science and Technology, Liuzhou, 545006, China
}

\begin{abstract}
Field electron emission currents from nanostructured films always have unsatisfied stability. This paper introduces a photocurrent treatment technique to enhance the filed emission properties, and gives a kind of nanostructured indium oxide film suitable for the technique. The products were prepared on patterned ITO glass substrate by using chemical vapor deposition method. With the increase of reaction time, the morphologies of the films changed from cocoonlike particles to hybrid thin films, and finally flowerlike nanostructures were formed. Photocurrent and field electron emission characteristics of the products have been studied. After photocurrent treatment, the flowerlike indium oxide films show stable field emission current (fluctuation is less than 5\%), low field emission threshold (at $7.5 \mathrm{~V} / \mathrm{m}$, the current density is $1 \mathrm{~mA} / \mathrm{cm}^{2}$ ) and high enhancement factor of electrical field of 778. The field emission test results validated that the photocurrent treated flowerlike indium oxide films may act as electron emitters and applied in display applications.
\end{abstract}

\section{Introduction}

Field electron emission characteristics of various nanostructured films have been extended reported since they have they have huge commercial benefits in display monitors and other electronic devices. Indium oxide is one of the most attractive electrode materials for field emission applications owing to its convenience of n-type doping, low electron affinity, high transparency and good electrical conductivity [1]. Moreover, indium oxide films have potential applications in acting as electron emission emitters. Hongbo Jia reported the field emission current density of the nanopyramids greater than $10^{3} \mu \mathrm{A} / \mathrm{cm}^{2}$ at a $6.0 \mathrm{~V} / \mu \mathrm{m}$ electrical threshold field [2]. Liqing $\mathrm{Hu}$ reported that the aligned $\mathrm{In}_{2} \mathrm{O}_{3}$ nanowires have turn-on field of $7.0 \mathrm{~V} / \mu \mathrm{m}$ and threshold field of $13.7 \mathrm{~V} / \mu \mathrm{m}$ [3]. However, the field emission performace of indium oxide is not as good as other materials such as carbon nanotubes [4] and zinc oxide [5]. In particular, its field electron emission currents always have unsatisfied stability. In order to enhance the field electron emission performace of indium oxide, we present a photocurrent treatment technique, and looking for a suitable material preparation process.

Various synthetic methods have been used to synthesize $\mathrm{In}_{2} \mathrm{O}_{3}$ nanostructured films, such as spray pyrolysis, sol-gel technique, pulse laser deposition, reactive thermal evaporation, direct oxidation and other methods [6]. In the study, we propose a relatively simple CVD method [7] to prepare flowerlike $\mathrm{In}_{2} \mathrm{O}_{3}$ film on patterned ITO glass substrates. Flowerlike $\mathrm{In}_{2} \mathrm{O}_{3}$ nanostructured thin films can be prepared by one step method with inorganic compounds as precursors at temperature of about $300^{\circ} \mathrm{C}$ without other catalysts. With the increase of reaction time, the morphology of the microstructures changed from cocoonlike particles to hybrid films, and finally flowerlike microstructures were formed. We have studied the field electron emission characteristics of the prepared products, and validated that the photocurrent treated flowerlike indium oxide nanostructured films may act as emitters and applied in display applications.

\section{Experimental}

ITO glass substrates were firstly etched by hydrochloric acid to form certain patterns of electrode (in this study, the ITO electrode was patterned by several letters of 'GXUT', as shown in Fig. 1), and then were placed into a tube furnace to carried out chemical vapor deposition (CVD) technological process. A given amount of $\mathrm{InCl}_{3}$ was placed on the central porcelain ship of the tubular furnace as the source of indium oxide. The patterned ITO glass substrate was placed directly above the porcelain boat. The reaction distance between ITO substrate and the raw material was about $3 \mathrm{~cm}$. The synthesis process consists of the following steps: when the furnace temperature rises to $400^{\circ} \mathrm{C}$ at a rate of $30^{\circ} \mathrm{C} / \mathrm{min}, \mathrm{N}_{2}$ gas is first filled into the reactor; then $\mathrm{NH}_{3} / \mathrm{H}_{2} \mathrm{O}$ mixture is maintained at $20 \mathrm{~cm}^{3} / \mathrm{min}$ during the reaction; and finally $\mathrm{N}_{2}$ is downstream to room temperature. After the temperature of

\footnotetext{
a Corresponding author: 1545767299@qq.com
} 
furnace slowly cooled to $25^{\circ} \mathrm{C}$, a thin yellow film can be seen on the surface of the ITO glass.

The morphology and structure of $\mathrm{In}_{2} \mathrm{O}_{3}$ thin films were studied by FEI Sirion QUANTA400 scanning electron microscopy (SEM). The X-ray spectrometer (EDX) was used to analyze the chemical composition. In the experiment, the acceleration voltage is $20 \mathrm{kV}$, and the detection angle is 30 degrees. SEM and EDX data were obtained on the film without removing the indium oxide on the glass surface. The XRD samples were obtained by collecting products prepared on the surface of patterned ITO glass substrates.

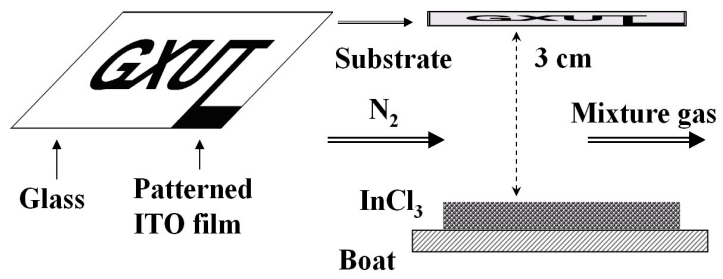

Figure 1. Sketch map of the synthesis method of indium oxide films.

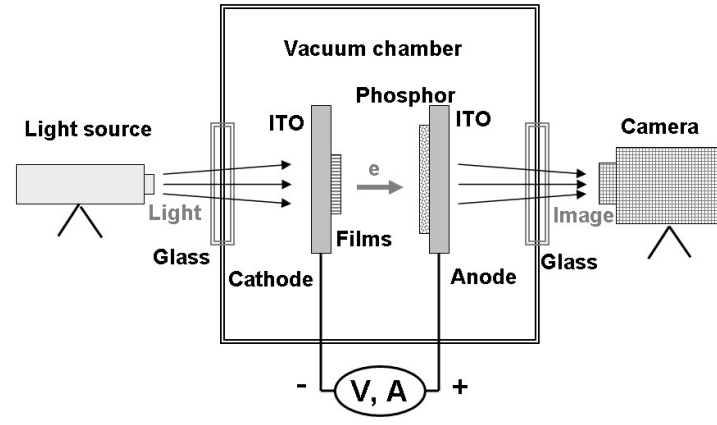

Figure 2. Field emission test and treatment device

In the photocurrent treatment process, the field emission characteristics were measured in a vacuum chamber with a diode field emission measurement structure, the vacuum gap is 0.25 $\mathrm{mm}$, the vacuum pressure is $4.0 \times 10^{-5} \mathrm{~Pa}$, as shown in Figure 2. The voltage between the two electrodes of the field emitter is slowly increased to suitable values.After we record the field emission current curves without treatment, we adjust the position of light source and irradiate the light on the cathod film. The illumination lasted for about 20 minutes, and record the fluctuation of field emission current until the current become stable. And then we record the relevant data and images of field emission from cathod film and analyze the results.

\section{Results and discussion}

In the process of experiments, several groups of samples were prepared, and their XRD spectra are basically the same. Typical XRD spectra of the films are shown in Fig. 3a. The films show strong peaks corresponding to (2 222$),\left(\begin{array}{lll}4 & 0 & 0\end{array}\right),\left(\begin{array}{lll}4 & 0 & 0\end{array}\right)$ and $\left(\begin{array}{lll}6 & 2 & 2\end{array}\right)$ planes at $30.58^{\circ}, 35.46^{\circ}, 51.03^{\circ}$, and $60.67^{\circ}$, respectively. These peaks correspond to indium cubic indium oxide (JCPDS card 06-0416). Fi. 3b indicate the existence of In and $\mathrm{O}$ elements on the membrane. $\mathrm{Si}, \mathrm{Ca}, \mathrm{Na}$ and $\mathrm{C}$ peaks originated from glass substrates. The peaks of other impurities were not detected in the spectra, indicating that the prepared films were pure $\mathrm{In}_{2} \mathrm{O}_{3}$.

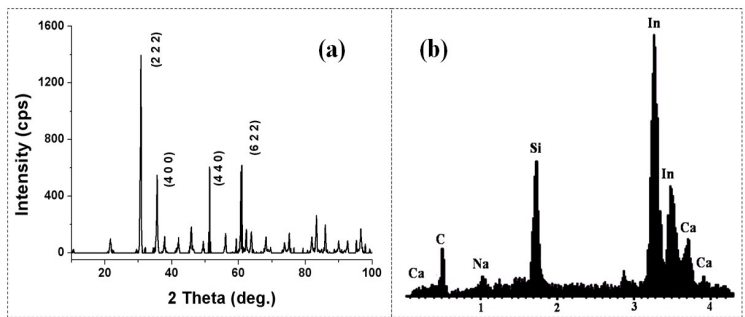

Figure 3. (a) Typical XRD pattern of the prepared products. (b) Typical EDX spectrum of the prepared products.

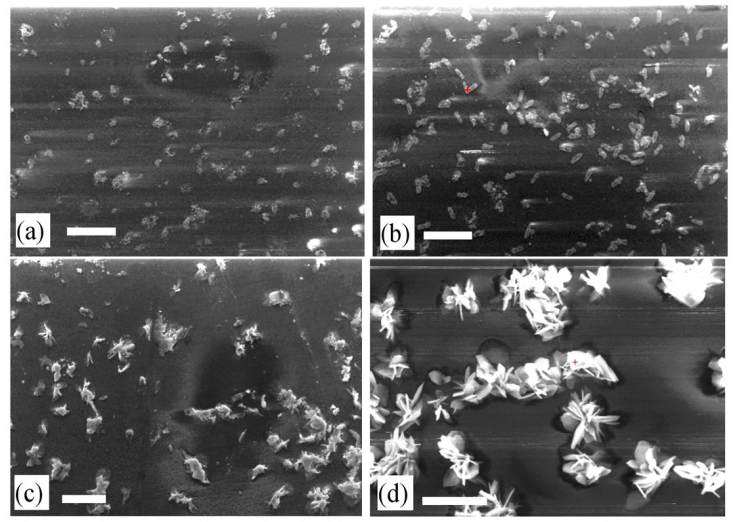

Figure 4. The growth process of nanostructured indium oxide films at different reaction times: (a) 10 minutes, (b) 1 hour, (c) 2 hours, and (d) 3 hours. The scale bar is $5 \mu \mathrm{m}$.

Fig. 4 shows the SEM image of the prepared indium oxide films at different reaction times. The growth process of $\mathrm{In}_{2} \mathrm{O}_{3}$ thin films is described as below: After reaction at $400^{\circ} \mathrm{C}$ for 10 minutes, some cocoon-like particles are deposited on glass substrates as the nuclei of the microstructure (Fig. 4a). By extending the reaction time to 1 hour (Fig. 4b) and 2 hours (Fig. 4c), some cocoon-like particles attempted to transform directly into flowerlike microstructure. With the increase of reaction time to 3 hours, almost all the aggregates grew into flowerlike microstructures, which were uniformly distributed and less overlapping, with a diameter of about $3 \mu \mathrm{m}$ (Fig. 4d). In Fig. 5, TEM micrographs (Fig. 5a) and flower like microstructure of cocoon like particles (Fig. 5b) are shown. The insets in Fig. 5 is the corresponding SAED pattern of the $\mathrm{In}_{2} \mathrm{O}_{3}$ thin films. It is difficult to determine the direction of growth of cocoon like particles and flower like nanostructures. It can be seen from Fig. 5 that the length of the cocoon-like particles is about $1 \mu \mathrm{m}$, and the diameter is about $200 \mathrm{~nm}$, while the flowerlike $\mathrm{In}_{2} \mathrm{O}_{3}$ film is composed of a slightly larger bonded sheet than that of the cocoonlike particles. 


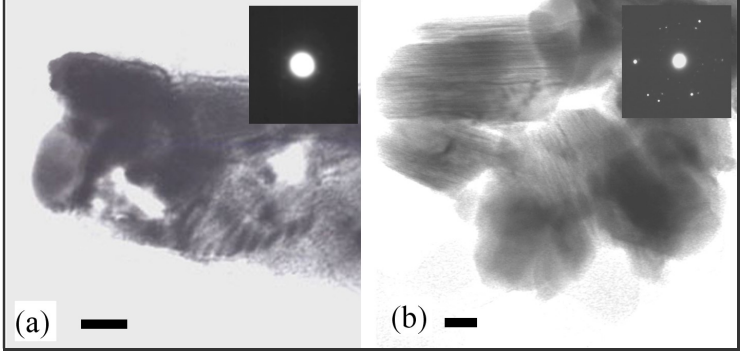

Figure 5. Electron microscopy of: (a) cocoonlike particles, (b) flowerlike nanostructures. Insets are the SAED patterns of the products. The scale bar is $50 \mathrm{~nm}$.

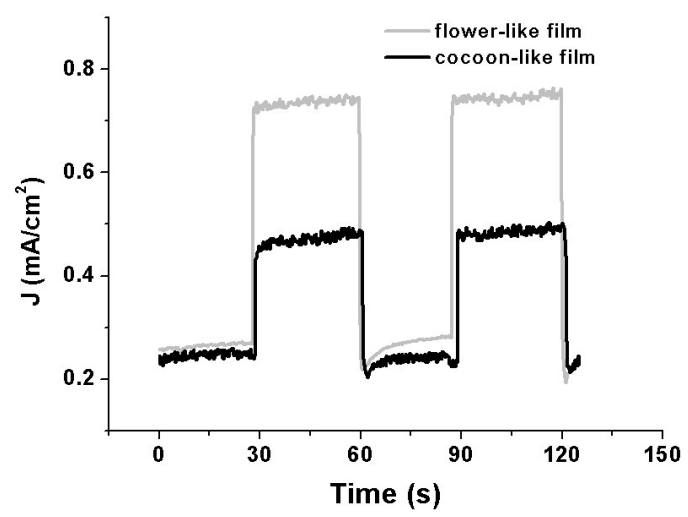

Figure 6. Photoelectric on-off effect of the indiumn oxide films before treatment.

We put the samples of cocoonlike particles and flowerlike nanostructures into a vacuum chamber, and then test the photoelectric characteristics of them. The test environment is in a dark room, the illumination of light on the samples is $150 \mathrm{k}$ Lux. We find that both the cocoonlike particles and flowerlike nanostructures show obviously on-off effect, but the flowerlike nanostructures are more intense. The stronger photocurrent makes the processing effect of flowerlike nanostructures are much better than that of cocoonlike particles. There are many reports that large current is used for field emission post treatment [8]. In our experiments, we need to get more strong current by the illumination of light [9], and make the effect of the post treatment become more obvious.

Fig. 7 shows that the emission current density of the prepared films variy with time in the process of photocurrent treatment. It can be seen from Fig.7 that the field electron emission currents of the two kinds of films increase gradually and then change smoothly. This means that our post treatment process has achieved good results. The photocurrent treatment last for about 20 minutes, and then we test the field emssion properties of the photocurrent treated samples.

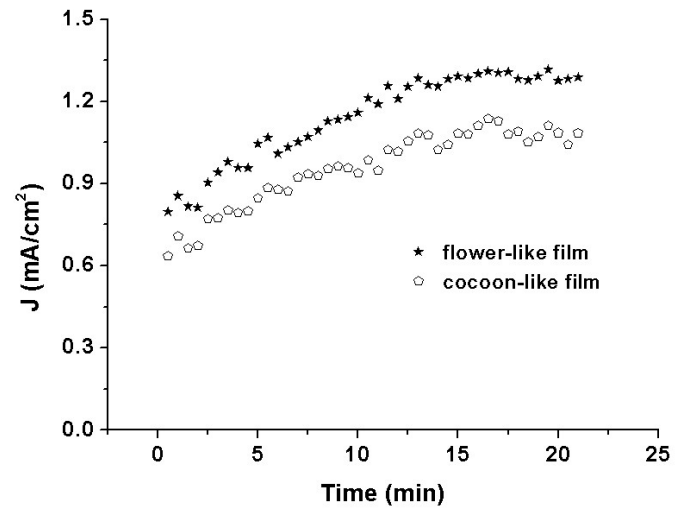

Figure 7. Current densities over time of the indiumn oxide films in the process of photocurrent treatment.

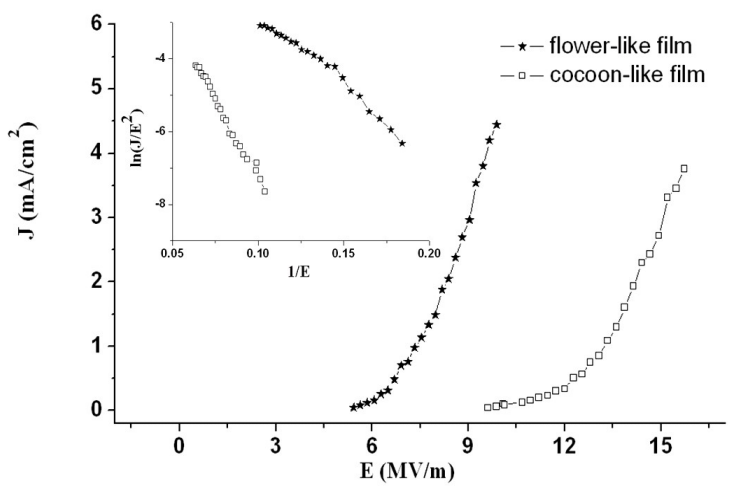

Figure 8. The relationship between the field emission current density and the electric field (J-E) curves of the photocurrent treated indiumn oxide films. The inset is the Fowler-Nordheim (F-N) graph of the J-E curves.

Fig. 8 gives the relationship between the typical field emission current density and the electric field (J-E curve), and Fowler-Nordheim (F-N) graph of the corresponding photocurrent treated products.

For photocurrent treated cocoon-like particles, the J-E curve shows that the threshold field (the required electric field to obtain $1 \mathrm{~mA} / \mathrm{cm}^{2}$ current density) is about $10.1 \mathrm{MV} / \mathrm{m}$, and the turn on field (the required electric field to obtain $10 \mu \mathrm{A} / \mathrm{cm}^{2}$ current density) is about $13.3 \mathrm{MV} / \mathrm{m}$. For the photocurrent treated flowerlike nanostructure, the results showed a lower turn on field is about $5.8 \mathrm{MV} / \mathrm{m}$, and a lower threshold field of is about $7.5 \mathrm{MV} / \mathrm{m}$.

The equation of Fowler-Nordheim can be written as below:

$$
J=1.54 \cdot 10^{5} \cdot \beta^{2} \cdot E / \varphi \cdot \exp \left(-6.83 \times 10^{3} \cdot \varphi^{3 / 2} / \beta / E\right)
$$

where $E$ is the applied field $(\mathrm{MV} / \mathrm{m}), \varphi$ is the work function of emitters $(\mathrm{eV}), J$ is the field emission current density $\left(\mathrm{mA} / \mathrm{cm}^{2}\right)$, and $\beta$ is the factor of electrical field enhancement. The work function of indium oxide is about $3.6 \mathrm{eV}$, therefore it can be calculated from Fig. 5 that the field enhancement factor of the cocoonlike particle is about 253 , and the field enhancement factor of the flowerlike film is about 778. These parameters of field emission properties of indium oxide films are close to those of zinc oxide films and carbon nanotubes. 


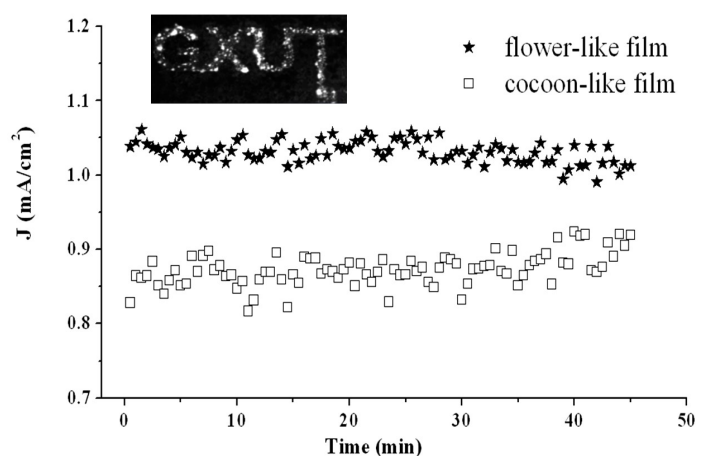

Figure 9. The emission current stabilities of the photocurrent treated indiumn oxide films. The inset is the corresponding typical field emission image.

Fig. 9 shows the emission current stabilities of the photocurrent treated products. For cocoonlike particles and the flowerlike films, the fluctuation of the emission current densities of them are about $10.5 \%$ and $5.0 \%$. All results above show that the flowerlike films have better field emission characteristics than cocoonlike particles. It may be owing to the flowerlike films have a relatively rough surface. The rough surface has a high field enhancement factor, and provides relatively stable electron emission. Compared with nanopyramids and nanowires, flowerlike indium oxide films have similar field emission characteristics and a lower synthesize temperature of $400^{\circ} \mathrm{C}$. This advantage insures that flowerlike indium oxide films can use ITO film as substrates. The inset of Fig. 9 shows the typical film emission image of the flowerlike indium oxide films prepared on patterned ITO glass. Several letters of 'GXUT' can be easily recognized, it validated that the photocurrent treated flowerlike indium oxide films may act as electron emitters and applied in flat panel display applications.

\section{Conclusion}

In summary, two types of indium oxide films were synthesised on the surface of patterned ITO glass substrates by using chemical vapor deposition method at $400^{\circ} \mathrm{C}$. The photocurrent treated flowerlike indium oxide films show a low field emission threshold, a high field enhancement factor, and a stable current density. Using indium oxide films as field electron emitters may provide an economical and reliable route for potential applications of display and other electron devices.

\section{Acknowledgments}

The authors acknowledge the financial support from the projects of National Natural Science Foundation of China (61464001) and Doctorial Science Foundation (1009) of Guangxi University of Science and Technology.

\section{References}

1. Tikhii A A, Nikolaenko Y M, Zhikhareva Y I, et al. Influence of the Thermal Conditions of Fabrication and Treatment on the Optical Properties of $\mathrm{In}_{2} \mathrm{O}_{3}$ films. Semiconductors, 2018, 52 (3): 320-323.

2. Jia H, Zhang Y, Chen X, et al. Efficient field emission from single crystalline indium oxide pyramids. Applied Physics Letters, 2003, 82 (23): 4146-4148.

3. $\mathrm{Hu} \mathrm{L} \mathrm{Q}$, Lin $\mathrm{Z} X$, Guo $\mathrm{T} \mathrm{L}$, et al. Field-emission properties of aligned and unaligned $\mathrm{In} 2 \mathrm{O} 3$ nanowires. Acta Physica Sinica, 2006, 55 (11): 6136-6140.

4. Xing Y, Zhang Y, Xu N, et al. Design and Realization of Microwave Frequency Multiplier Based on Field Emission from Carbon Nanotubes Cold-Cathode. IEEE Transactions on Electron Devices, 2018, 65 (99): 1-5.

5. Ding S, Zhou Y, Ye M, et al. Stable field emission from $\mathrm{ZnO}$ nanowires grown on 3D graphene foam. Vacuum, 2017, 139: 33-36.

6. Zhang S, Song P, Tian Z, et al. Synthesis of mesoporous $\mathrm{In} 2 \mathrm{O} 3$ nanocubes and their superior trimethylamine sensing properties. Materials Science in Semiconductor Processing, 2018, 75: 58-64.

7. Biegger F, Jungwirth F, Seifner $M \quad S$, et al. Aerosol-assisted CVD of thioether-functionalised indium aminoalkoxides. Monatshefte Fur Chemie, 2017, 148 (8): 1385-1392.

8. Li Z L, Liu F, Xu N S, et al. Improving field-emission uniformity of large-area W18049 nanowire films by electrical treatment. Journal of vacuum science \& technology B, 2009, 27 (6): 2420-2425.

9. Arkhipov A V, Gabdullin P G, Gordeev S K, et al. Photostimulation of conductivity and electronic properties of field-emission nanocarbon coatings on silicon. Technical Physics, 2017, 62 (1): 127-136. 